\title{
EVALUATION OF ROLE OF PREOPERATIVE LAPAROSCOPY IN ABDOMINAL MALIGNANCIES.
}

Nilesh P Tulaskar, Prabhat Nichkaode, Subrajit Dasgupta, Abhay Choudhary

Kapil Panchbhai, Rahul Zamad

1. Assistant Professor. Department of General Surgery, NKP Salve institute of Medical Sciences, Nagpur.

2. Associate Professor. Department of General Surgery, NKP Salve institute of Medical Sciences, Nagpur.

3. Professor. Department of General Surgery, NKP Salve institute of Medical Sciences, Nagpur.

4. Assistant Professor. Department of General Surgery, NKP Salve institute of Medical Sciences, Nagpur.

5. Assistant Professor. Department of General Surgery, NKP Salve institute of Medical Sciences, Nagpur.

6. Junior Resident. Department of General Surgery, NKP Salve institute of Medical Sciences, Nagpur.

\author{
CORRESPONDING AUTHOR: \\ Dr. Nilesh Tulaskar, \\ Dept of Surgery, \\ Lata Mangeshkar Hospital, \\ Digdoh Hill, Nagpur- 440019. \\ E-mail: nileshtulaskar@yahoo.com
}

ABSTRACT: BACKGROUND AND AIMS: Many surgeons worldwide had challenging experience of facing an unexplainable and uncertain diagnosis or staging of abdominal malignancies. Laparoscopic visualisation techniques have improved dramatically and had led to reassessment of the laparoscope for use in the staging of intraabdominal malignancies. To evaluate place of preoperative laparoscopy as an additional tool to diagnose, assess staging and operability of intraabdominal tumors. SETTINGS AND DESIGN: A prospective observational case series. MATERIALS AND METHODS: Thirty five consecutive cases undergoing preoperative staging laparoscopy from December 2008 to September 2010 were reviewed in order to determine the value of laparoscopy as a staging tool. Indications for staging laparoscopy were predominantly hepatopancreaticobiliary (45\%); however, other primaries such as stomach and colon were included. RESULTS: Unnecessary laparotomies prevented in 57.14\% of cases. Metastatic spread detected by laparoscopy was in $40 \%$ of cases. The sensitivity and specificity of laparoscopy in Abdominal malignancies to detect resectable disease is $65.3 \%$ and $100 \%$ respectively. CONCLUSIONS: laparoscopy is a useful preoperative staging tool and can help avoid unnecessary laparotomy for abdominal malignancy in one- half of cases.

KEYWORDS: Laparoscopy, Laparotomy, Staging, Abdominal Malignancies.

INTRODUCTION: A diagnostic surprise or finding a tumor unresectable at laparotomy is a situation which every surgeon wants to avoid. A proper diagnosis, pre therapeutic staging, an assessment of resectability in abdominal malignancy are important to group patient for treatment strategy. Despite an increased sophisticated radiological diagnostic modalities like $\mathrm{CT}, \mathrm{MRI}$, many patients with gastric, hepatic, pancreatic malignancy continue to have diagnosis of unresectable or metastatic disease made at exploratory laparotomy. Laparoscopic examination can visualize primary tumor, identify hepatic metastasis, regional nodal metastasis and intraperitoneal metastasis, which at times may not be picked up by imaging modalities ( 1 , 3 ). Diagnostic Laparoscopy can benefit patient by avoiding unnecessary surgery, unnecessary delay in diagnosis and treatment and shortening operative and hospitalized periods. The usefulness and efficacy of laparoscopy as a preoperative tool for diagnosis, evaluation, staging 
and assessment of intraabdominal malignancy are the areas which need evaluation and assessment in order to standardise the procedure and bring in into more regular use.

The aim and objective of our study were to evaluate preoperative laparoscopy as an additional tool to diagnose, assess staging and operability of intraabdominal tumors and whether preoperative laparoscopic assessment makes a significant change in decision making regarding and protocol of treatment.

MATERIALS AND METHODS: This prospective observational study was carried out from 2008 to 2011 at a rural-based tertiary care hospital located in Central India. Patients were eligible if the all of the following criteria were met

- Patients investigated and diagnosed of abdominal malignancy.

- Undifferentiated or unstaged abdominal malignancy in all adult patients.

The patients excluded who have unstable hemodynamic conditions, respiratory distress, severe coagulation defects, evidence of peritonitis, pregnancy, traumatological emergencies, immediate Post operative patients, re-exploration, Gross Ascites, and intraabdominal malignancy presenting with acute and sub-acute intestinal obstruction.

All patients with abdominal malignancy diagnosed by radiological criteria were submitted to staging laparoscopy before a planned open exploration and resection.

All data entered into excel data base from paper proforma. Data base were analysed. All results were expressed in the form of numbers and percentage. The outcome of the study were analysed by sensitivity and specificity.

RESULTS: A total of 35 patients of intraabdominal malignancies were enrolled in the study. The mean age of presentation was 52 years with a range between 18 years to 72 year. Out of 35 patients, $16(46 \%)$ patients were male and $19(54 \%)$ patients were females.

Out of 35 patients, 7 (20\%) patients were of carcinoma stomach, 10 (28.5\%) patients were of colorectal malignancy, 5 (14.3\%) patients were of Gall bladder malignancy, 4 (11.5\%) patients were of Periampullary carcinoma, 2 (5.7\%) patients were of Hilar cholangiocarcinoma, $5(14.3 \%)$ patients were of Carcinoma head of pancreas and $2(5.7 \%)$ patients were of ovarian malignancy. (Table no. 1)

Table No 1: Distribution according to Type of Cancer (n- 35)

\begin{tabular}{|c|c|c|}
\hline Type of Cancer & No. of patients(n) & Percentage (\%) \\
\hline Stomach & 7 & $20 \%$ \\
\hline Colorectal & 10 & $28.5 \%$ \\
\hline Gall bladder & 5 & $14.3 \%$ \\
\hline Periampullary & 4 & $11.5 \%$ \\
\hline Hilar cholangiocarcinoma & 2 & $5.7 \%$ \\
\hline Head of pancreas & 5 & $14.3 \%$ \\
\hline Ovarian & 2 & $5.7 \%$ \\
\hline Total & 35 & $100 \%$ \\
\hline
\end{tabular}


Table no. 2 and Table no . 3 show distribution of intraabdominal metastasis and reasons for unresectability

Table No. 2 : Distribution of intraabdominal metastasis

\begin{tabular}{|c|c|c|c|c|c|}
\hline $\begin{array}{c}\text { Primary } \\
\text { origin of } \\
\text { malignancy }\end{array}$ & $\begin{array}{c}\text { No. of } \\
\text { patients }\end{array}$ & $\begin{array}{c}\text { Locoregional } \\
\text { metastatic } \\
\text { spread detected } \\
\text { by USG/CT/MRI }\end{array}$ & $\begin{array}{c}\text { Percentage } \\
\text { \% }\end{array}$ & $\begin{array}{c}\text { Metastatic } \\
\text { spread } \\
\text { detected by } \\
\text { laparoscopy }\end{array}$ & $\begin{array}{c}\text { Percentage } \\
\%\end{array}$ \\
\hline Stomach & 7 & 1 & $14.28 \%$ & 2 & $28.57 \%$ \\
\hline Colorectal & 10 & 0 & $0 \%$ & 3 & $30 \%$ \\
\hline Gall Bladder & 5 & 4 & $80 \%$ & 4 & $80 \%$ \\
\hline Pancreas & 5 & 2 & $40 \%$ & 3 & $60 \%$ \\
\hline Cholangio ca & 2 & 0 & $0 \%$ & 2 & $100 \%$ \\
\hline Periampullary & 4 & 0 & $0 \%$ & 0 & $0 \%$ \\
\hline Ovarian & 2 & 0 & $0 \%$ & 0 & $40 \% \%$ \\
\hline Total & 35 & 7 & $20 \%$ & 14 & \\
\hline
\end{tabular}

Table No. 3 Distribution according to reasons for Unresectability

\begin{tabular}{|c|c|c|c|c|c|}
\hline & \multicolumn{5}{|c|}{ Reasons for unresectability } \\
\hline $\begin{array}{c}\text { Type of } \\
\text { cancer }\end{array}$ & $\begin{array}{c}\text { Lymph } \\
\text { nodal } \\
\text { metastasis }\end{array}$ & $\begin{array}{c}\text { Peritoneal/omental } \\
\text { metastasis }\end{array}$ & $\begin{array}{c}\text { Vascular } \\
\text { encasement }\end{array}$ & $\begin{array}{c}\text { Fixity to } \\
\text { adjacent } \\
\text { structures }\end{array}$ & $\begin{array}{c}\text { Liver } \\
\text { metastasis }\end{array}$ \\
\hline Stomach & 5 & 2 & 1 & 3 & 2 \\
\hline Colorectal & 5 & 3 & 0 & 4 & 3 \\
\hline Gall Bladder & 5 & 2 & 0 & 4 & 4 \\
\hline Pancreas & 4 & 2 & 4 & 4 & 3 \\
\hline Cholangio ca & 2 & 1 & 0 & 2 & 1 \\
\hline Periampullary & 1 & 0 & 0 & 0 & 0 \\
\hline Ovarian & 0 & 0 & 6 & 18 & 13 \\
\hline Total & 22 & 10 & $17.2 \%$ & $51.4 \%$ & $37.1 \%$ \\
\hline Percentage \% & $62.8 \%$ & $28.6 \%$ & & 1 & 0 \\
\hline
\end{tabular}


Table no. 3 shows lymph nodal metastasis in 22 patients.This nodal metastasis are fixed and difficult to remove because they were situated along the vascular structures. It is not possible to separate growth from nodal mass in some cases. For e.g. . in gastric malignancies, nodal mass along left gastric artery which were fixed and difficult to remove.

\section{Distribution according to outcome: Table 4}

The sensitivity and specificity of laparoscopy in Abdominal malignancies to detect resectable disease is $65.3 \%$ and $100 \%$ respectively.

Table No. 4 Distribution according to outcome of laparoscopy

\begin{tabular}{|c|c|c|c|}
\hline Laparoscopy (n- 35) & \multicolumn{2}{|c|}{ Computed Tomography } & \\
\hline Outcome & Resectable & Unresectable & Total \\
\hline Resectable & 15 & 0 & 15 \\
\hline Unresectable & 8 & 12 & 20 \\
\hline Total & 23 & 12 & 35 \\
\hline \multicolumn{4}{c}{$\mathbf{0 . 0 0 0 2}(\mathbf{S})$}
\end{tabular}

FISHER'S EXACT TEST: The two-tailed P value equals 0.0002 The association between Laparoscopy and computed tomography is considered to be extremely statistically significant.

DISCUSSION: Noninvasive staging plays an important role in the therapeutic approach of gastrointestinal malignancies. Recently, laparoscopy in combination with laparoscopic ultrasonography has been introduced as an additional procedure. A variety of results are reported in the literature showing a rate of avoided laparotomies between 5\% and 64\%, depending on the type of tumor. (6)

GASTRIC CANCER: Burke et al (9) published their study of 111 gastric cancer patients who underwent laparoscopy. In this study of 111 patients with gastric cancer judged to be free of metastatic disease by preoperative CT, laparoscopy diagnosed metastatic disease in 32 patients, with an overall accuracy of $94 \%$.

Kriplani and Kapur et al (4) who reported a diagnostic accuracy of $92 \%$ for laparoscopic staging. In their series of 40 patients, Laparoscopy revealed metastases in five $(13 \%)$ and locally advanced disease in $11(28 \%)$ cases.

Similarly, Ajani and colleagues (10) reported on 39 patients with clinically staged, localized lesions who underwent laparoscopy. Of these, eight (21\%) were found to have gross peritoneal disease.

The high percentage of peritoneal metastases (62.5\%) published by Song et al (11) can be explained by selective staging for T3-T4 gastric tumors.

In our present study, total 7 patients of gastric malignancies who underwent preoperative laparoscopy revealed peritoneal and liver metastasis in $2(28.57 \%)$ patients and locally advanced disease in $3(42.8 \%)$ patients. Unresectability was predicted in 5 (71.4\%) patients with diagnostic accuracy of $100 \%$. Thus our study correlates with studies conducted by Burke et al (9), Kriplani and Kapur et al (4). 
PANCREATIC CANCER: Most patients with pancreatic cancer have metastatic disease and cannot benefit from surgery. However, even with the advancement of radiographic imaging, it can be difficult to determine which patients are candidates for resection and minimally invasive surgery may help avoid unnecessary diagnostic laparotomies.

Jiminez et al (12) found that laparoscopy diagnosed unsuspected metastases in $31.2 \%$ of patients with pancreas cancer, thus avoiding non therapeutic laparotomy. Reddy $\mathrm{K} \mathrm{R}$ et al (13) indicate that staging laparoscopy can detect unresectable disease in $20 \%$ to $48 \%$ of patients felt to be resectable by CT scan.

Conlon et al (5) have reported an accuracy rate of 98\% for staging laparoscopy in pancreatic cancer. In a series of 115 patients, Conlon and colleagues reported good results in the detection of extrapancreatic tumor extension: from 67 patients considered as resectable on laparoscopy, only $6(9 \%)$ patients were unresectable on laparotomy.

Syed Ahmed et al (14) reported the series of 59 patients. Out of 37 patients, laparoscopy detected metastatic or advanced disease in 9 patients $(24.3 \%)$ ). Of the 22 patients who did not undergo laparoscopy, 6 patients $(27.2 \%)$ had unresectable tumors and might have benefited from laparoscopy.

In our present study, 5 patients of pancreatic malignancies underwent preoperative laparoscopy. Laparoscopy detects metastatic disease in $3(60 \%)$ patients as compared to CT i.e. $2(40 \%)$ and locally advanced disease in $4(80 \%)$ patients. Unresectability predicted in $4(80 \%)$ patients. Thus avoiding laparotomy in $4(80 \%)$ patients. The overall efficacy of laparoscopy was $80 \%$.

The results of our study shows higher percentage of accuracy of laparoscopy to detect unresectability as compared to above mentioned studies. This is because of limited sample size.

BILIARY TRACT TUMORS: Biliary tract tumors can be divided into two main categories: gallbladder cancers and cholangiocarcinomas. The two groups differ in their patterns of spread and their prognoses. Gallbladder cancer tends grow more rapidly, with earlier dissemination, which makes SL a more useful tool in this setting.

Weber et al (17) assessed the role of staging laparoscopy in 100 patients of extrahepatic biliary tract tumors predicting unresectability in $35 \%$ of patients. Similarly Tilleman et al (18) and Goere et al (19) predicting unresectability in $41.8 \%$ and $36 \%$ of patients.

In our present study, 5 patients of Gall Bladder malignancies and 2 patients of cholangiocarcinomas were undergone preoperative laparoscopy. In gall bladder cancers, laparoscopy detects metastatic disease in $4(80 \%)$ patients predicting unresectability in $80 \%$ of patients. The overall efficacy of laparoscopy was $80 \%$.

Table 4 Studies assessing the role of staging laparoscopy in biliary tract tumor Table 4 Studies assessing the role of staging lapor able 4 StudiWe had 2 patients of cholangiocarcinoma in which laparoscopy detects metastatic and advanced disease in both 2 patients $(100 \%)$ predicting unresectability in 2 patients. Thus overall efficacy of laparoscopy was $100 \%$.

Thus in our study overall efficacy of laparoscopy to detect unresectability in biliary tract cancers was $85.7 \%$. Our study shows highest efficacy compared to above mentioned studies because we advocated the use of staging laparoscopy in potentially unresectable primary gall bladder cancer and patients with T3/T4 hilar cholangiocarcinomas. 
PERIAMPULLARY MALIGNANCIES: Ari D and Brooks et al (15) performed laparoscopy in134 cases of Ampullary and distal bile duct tumors. Laparoscopy identified 13 patients $(10 \%)$ with unresectable disease. Of 121 patients with laparoscopic resectable disease, 111 (92\%) went on to subsequent resection; CT correctly predicted resectability in $82 \%$. Laparoscopy spared $36 \%$ of unresectable patients a non therapeutic laparotomy.

Christopher J et al (16) revealed that overall resectability rate for all periampullary cancers was $67.3 \%$ (115 of 171 patients). 56 (34.7\%) patients with periampullary cancers were unresectable because of metastatic disease.

In our present study, 4 patients underwent preoperative laparoscopy. Laparoscopy detects metastatic and locally advanced disease in $1(25 \%)$ patients predicting resectability rate for periampullary cancers was 75\%.Thus overall efficacy of laparoscopy to detect unresectable disease was $25 \%$. Avoiding laparotomy in $25 \%$ of patients.

Thus, the results of our study almost correlate well with the studies conducted By Christopher et al.

COLORECTAL CANCERS: Rahusen et al (7) studied staging laparoscopy in 50 patients of colorectal cancers predicting unresectability in $38 \%$ of patients. Similarly Jarnagin et al (8) and Grobmyer et al predicting unresectability in $14 \%$ and $10 \%$ of patients respectively.

In our present study, 10 patients of colorectal cancers underwent laparoscopy. Laparoscopy detects metastatic disease in $3(30 \%)$ patients and locally advanced disease in 4 patients. Unresectability detected in $4(40 \%)$ patients. The overall efficacy was $40 \%$.

Our results of the study well correlate with Rahusen et al (7) study. Other studies show lower percentage of resectability.

CONCLUSION: Laparoscopy is highly accurate in detecting occult metastases and identifies a unique population of stage IV patients who may benefit from newer induction chemotherapeutic approaches while avoiding unnecessary laparotomy. Preoperative laparoscopic evaluation of a patient with intraabdominal malignancies is complementary to other imaging modalities in improving the yield of metastatic disease and accurate staging of disease process.

\section{REFERENCES:}

1 Kevin C, P. Conlon, Emery A. Minnard. et al. the Value of Laparoscopic Staging in Upper Gastrointestinal Malignancy -The Oncologist 1997;2:10-17.

2 Bruce J.Ramshaw. et al. Laparoscopic Surgery for Cancer Patients Cancer j Clin 1997; 47: 327 -350.

3 Hemming A.W, Nagy A.G, and Scud more C.H. et al. Laparoscopic staging of intraabdominal malignancy. Surg Endosc (1995) 9: p 325.

4 Kriplani A.K., Kapur B.M.L. Laparoscopy for the preoperative staging and assessment of operability in gastric cancer. Gastrointest Endosc (1991) 37: pp 441-443.

5 Conlon KC, Dougherty E, Klimstra DS, et al. The value of minimal access surgery in the staging of patients with potentially resectable peripancreatic malignancy. Ann Surg 223:134-140, 1996.

6 John TG, Greig JD, Crosbie JL, et al. Superior staging of liver tumors with laparoscopy and laparoscopic ultrasound. Ann Surg 220:711-719, 1994. 
7 Rahusen F.D., Cuesta M.A., Bergstein P.J., et al. Selection of patients for resection of colorectal metastases to the liver using diagnostic laparoscopy and laparoscopic ultrasonography. Ann Surg (1999) 230: pp 31-37.

8 Jarnagin W.R., Conlon K., et al. Clinical scoring system predicts the yield of diagnostic laparoscopy in patients with potentially resectable hepatic colorectal metastases. Cancer (2001) 91: pp 1121-1128.

9 Burke EC, Karpeh MS, Conlon KC, and Brennan MF (1997) Laparoscopy in the management of gastric adenocarcinoma. Ann Surg 225(3):262 267.

10 Ajani JA, Mansfield PF, Ota DM. Potentially resectable gastric carcinoma: current approaches to staging and preoperative therapy. World J Surg 1995; 19:216-220.

11 Song KY, Kim JJ, and Kim SN, Park CH. Staging laparoscopy for advanced gastric Cancer: is it also useful for the group which has an aggressive surgical strategy? World J Surg 2007; 31: 1228-3...

12 Jiminez RE, Warshaw AL, Rattner DW, et al. Impact of laparoscopic staging in the treatment of pancreatic cancer. Arch Surg. 1999;135:409-415.

13 Reddy KR, Levi J, Livingstone A, et al. Experience with staging laparoscopy in pancreatic malignancy. Gastrointest Endosc. 1999; 49:498-503.

14 Syed i. Ahmed, victor bochkarev, Dmitry oleynikov, and Aaron r. Sasson. Patients with pancreatic adenocarcinoma benefit From staging laparoscopy journal of laparoendoscopic \& advanced surgical techniques Volume 16, number 5, 2006.

15 Ari D. Brooks M.D., Michael J. Mallis, Jr. D.O., Murray F. Brennan M.D. and Kevin C. P. Conlon M.D. The Value of Laparoscopy in the Management of Ampullary, Duodenal, and Distal Bile Duct Tumors Journal of Gastrointestinal Surgery Volume 6, Issue 2, March-April 2002, Pages 139-146.

16 Christopher J. Barreiro, Keith D. Lillooet, Leonidas G. Koniaris, Taylor A. Sohn, Charles J. Yeo, JoAnn Coleman, Elliot K. Fishman and Cameron. Diagnostic laparoscopy for periampullary and pancreatic cancer: What is the true benefit? Journal of Gastrointestinal Surgery Volume 6, Number 1, 75-81.

17 Weber SM, DeMatteo RP, Fong Y, Blumgart LH, Jarnagin WR. Staging laparoscopy in patients with extrahepatic biliary carcinoma. Analysis of 100 patients. Ann Surg 2002; 235: 392-399.

18 Tilleman EH, de Castro SM, Busch OR, Bemelman WA, van Gulik TM, Obertop H, and Gouma DJ. Diagnostic laparoscopy and laparoscopic ultrasound for staging of patients with malignant proximal bile duct obstruction. J Gastrointest Surg 2002;426-430; discussion 430-431.

19 Goere D, Wagholikar GD, Pessaux P, Carrère N, Sibert A, Vilgrain V,Sauvanet A, Belghiti J. Utility of staging laparoscopy in subsets of biliary cancers : laparoscopy is a powerful diagnostic tool in patients with intrahepatic and gallbladder carcinoma. Surg Endosc 2006; 20: 721-725. 


\section{ORIGINAL ARTICLE}

Figure No. 1 Preoperative Laparoscopy showing locally advanced Gastric cancer

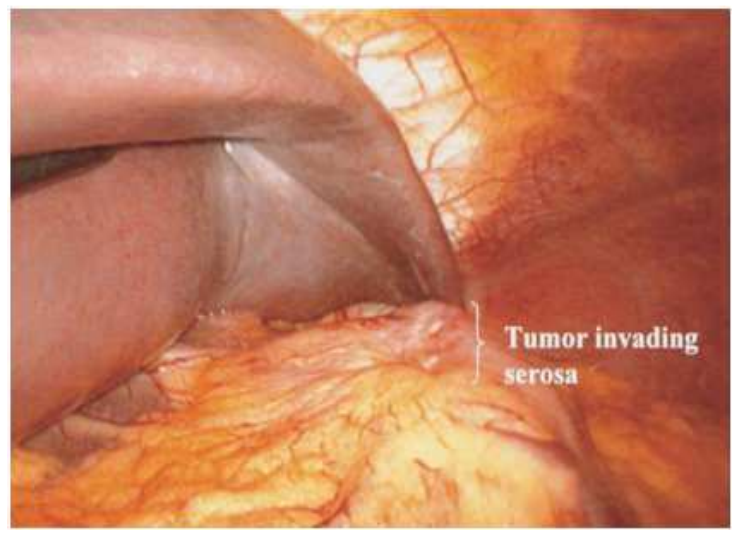

Figure No. 2 Preoperative laparoscopy of gastric cancer showing liver metastasis which was not detected by CT abdomen.

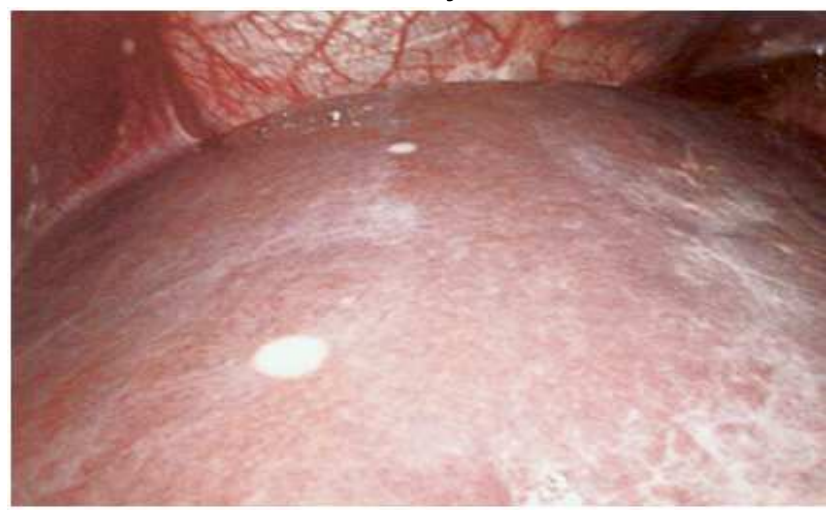

Figure No.3 Laparoscopy of Gastric cancer showing peritoneal metastasis not detected on CT abdomen

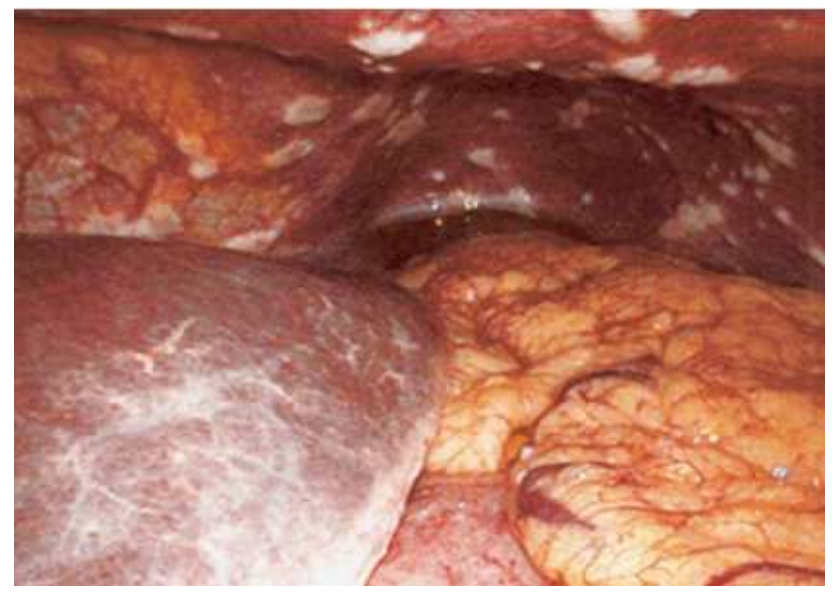

